\title{
O tema Coronavírus nOS Planos de estudos TUTORADOS DO ENSINO FUNDAMENTAL - ANOS FINAIS DO ESTADO DE MINAS GERAIS
}

\author{
THE CORONAVIRUS THEME IN THE TUTORED STUDY PLANS OF \\ ELEMENTARY SCHOOL - FINAL YEARS OF THE STATE OF MINAS GERAIS
}

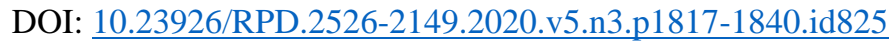

\section{Erisnaldo Francisco \\ Reis \\ Mestre em Ensino de \\ Ciências Exatas \\ (UNIVATES/RS) \\ Professor na Rede Estadual do Estado de Minas Gerais erisnaldo.reis@universo.univ ates.br}

\section{Andreia A. Guimarães} Strohschoen

Doutora em Ecologia (UFRGS)

Professora do Doutorado e Mestrado do PPGE e do PPGECE (UNIVATES). aaguim@univates.br
Resumo: A pandemia da COVID-19 modificou o processo educacional no país. Nesse viés, o objetivo deste estudo é relatar como o tema Coronavírus está apresentado nas atividades propostas pela escolas da rede estadual de ensino de Minas Gerais - Brasil. Trata-se de uma pesquisa com abordagem qualitativa, constituindose uma revisão bibliográfica, realizada a partir do Caderno 1 dos Planos de Estudos Tutorados do Ensino Fundamental Regular - Anos Finais, apresentados pela Secretaria Estadual de Educação do referido estado. Tais planos fazem parte do Regime Especial de Atividades Não Presenciais (REANP) proposto pela Secretaria. A análise foi realizada por disciplina e por semana, verificando-se, a incidência do tema nas unidades temáticas, no objeto de conhecimento, nas habilidades e nos conteúdos relacionados em cada plano. Os resultados apontam que o tema Coronavírus não foi apresentado em todas as disciplinas. Além disso, evidenciou-se que a temática não foi tratada com profundidade na maioria das atividades propostas.

Palavras-chave: Estudante. Professor. Conhecimento Científico. Covid-19. Pandemia.

\begin{abstract}
The COVID-19 pandemic has changed the educational process in the country. Accordingly, the aim of this study is to report how the Coronavirus theme is presented in the activities of the Plans for Tutored Studies-Notebook n.1, of Regular Elementary School Final Years of the State of Minas Gerais (MG), Brazil. This is a qualitative research, with a bibliographic review approach based on The Number One Notebook of The Plans for Tutored Studies of Regular Elementary School- Final Years, presented by the State Department of Education of the State of MG, which is part of the Special Regime of Non-Face-To-Face Activities - REANP. The observation occurred by discipline and per week. It was also verified, the thematic units, the object of knowledge, the skills and related contents. The results indicate that the Coronavirus theme is not presented in all disciplines, not being emphasized in part of the proposed activities of the disciplines.
\end{abstract}

Keywords: Student. Teacher. Scientific Knowledge. Covid-19. Pandemic. 


\section{INTRODUÇÃO}

Há anos, a educação no Brasil tem passado por diversas transformações na busca por melhoria da qualidade dos processos de ensino e de aprendizagem. No entanto, o contexto da pandemia causada pelo Coronavírus (COVID-19) forçou mudanças drásticas no campo educacional. A partir do momento em que a Organização Mundial da Saúde (OMS) declarou o estado de pandemia da COVID-19, recomendando o isolamento social como a estratégia mais eficiente para enfrentar o vírus, diminuindo o ritmo de sua propagação e, consequentemente, salvando vidas, muitas ações foram colocadas em prática. Dentre essas ações, houve o fechamento das fronteiras entre os países, foram paralisadas as atividades comerciais, houve interdição dos espaços de lazer e ocorreu a suspensão das atividades pedagógicas presenciais em escolas e universidades. Assim, tudo mudou de modo radical em nossas vidas, principalmente em decorrência do resguardo rigoroso a que as pessoas foram dispostas, o que, para muitos, tornou-se uma experiência bastante penosa (COUTO, et al. 2020).

Contudo, o isolamento social que ora se mostra em curso tem apresentado uma natureza distinta, ou seja, em tempos atuais os indivíduos não se isolam totalmente do mundo, visto que são muitos os recursos e meios de comunicação em rede que possibilitam as conexões sociais. $\mathrm{Na}$ esfera escolar, da mesma forma, recursos tecnológicos digitais foram utilizados na tentativa de dar continuidade aos processos educacionais.

Nessa perspectiva, considerando o contexto da pandemia, conjecturou-se uma possível abordagem do tema 'Coronavírus' nos materiais elaborados pelas escolas das redes estaduais. Assim, essa inquietação levou-nos a indagar: Como o tema 'Coronavírus' é apresentado nas atividades do Planos de Estudos Tutorados do Ensino Fundamental Regular - Anos Finais do Estado de Minas Gerais? A partir desse questionamento, define-se como objetivo deste artigo relatar como o tema Coronavírus foi abordado nas atividades propostas pelos Planos de Estudos Tutorados - Caderno 1, do Ensino Fundamental Regular - Anos Finais do Estado de Minas Gerais. Ainda de modo específico, este trabalho intenciona problematizar as atividades que fazem referência ao tema e verificar se há um aprofundamento para favorecer o conhecimento dos alunos acerca do vírus e da pandemia.

Pensa-se que, por se tratar de uma pandemia e a escola ser um meio de disseminar informação científica, estudos que analisem como esse tema é apresentado aos estudantes são relevantes. Assim, espera-se contribuir com informações que possibilitem refletir sobre a continuidade dos processos educacionais e sobre a forma com que o conhecimento científico é apresentado para os estudantes em tempos de pandemia. 


\section{REFERENCIAL TEÓRICO}

A verdade é que a pandemia nos colocou frente a uma série de desafios. Um desses desafios foi o de (re) pensar a escola. Kirchner (2020) assevera que a pandemia retirou da sala de aula - um ambiente que sempre foi o lugar de estabelecer os principais vínculos de mediações de conhecimento - os seus principais atores: os alunos e os professores. Kirchner (2020, p. 46) argumenta que "a função docente desempenhada dentro desse lugar, onde professores, alunos e toda comunidade escolar se habituaram, já não é o espaço delimitado para essa função".

De acordo com Badin et al.(2020), quando se trata de Educação Básica, há que se considerar que, nessa etapa, a base para o desenvolvimento do trabalho é a interação, a proximidade, o olhar, o toque e todos esses aspectos precisaram ser reinventados, dada a impossibilidade de aproximação exigida pela pandemia. Nesse sentido, houve uma quebra drástica na rotina escolar.

Uma sala de aula é marcada por um movimento de uma rotina intensa de afazeres. Nessa rotina, o tempo de pensar acerca de outras formas de ser e fazer a aula acaba sendo redimensionado para outros espaços de formação. Ao longo dos tempos, sempre se tem falado e buscado uma transformação da escola, exigindo repensar novos modelos. Agora, com o advento da pandemia, essa transformação aconteceu de maneira radicalmente abrupta (KIRCHNER, 2020). Segundo Silva (2020, p. 72), "a pandemia mudará muitas formas de estruturar a organização do trabalho pedagógico, seja pelas ações empreendidas nessa fase, sejam nos resultados dessas atividades, consideradas pedagógicas desenvolvidas no lar”.

Para Vieira e Ricci (2020, p. 5), “é necessário que o caminho percorrido e as aprendizagens desenvolvidas pelas redes e profissionais da educação para enfrentamento deste período de pandemia sejam mantidos como heranças vivas, permitindo-nos melhor configurar a escola pós-pandemia”. Portanto, compreende-se que a escola em qualquer época, enquanto espaço em que se desenvolve a aprendizagem, deve se preocupar não só com as experiências que consolidam o processo de educar, como também com as situações que tenham significado para os estudantes. É nesse aspecto que se coloca em foco a questão da pandemia provocada pela COVID-19, como ponto científico a ser aprofundado nas atividades remotas.

Assim, dentro desse contexto de pandemia, o isolamento social recomendado pelos Órgãos de Saúde competentes exigiu que as escolas suspendessem as atividades presenciais. Diante dessa situação, evidenciou-se, no Brasil uma ausência de política nacional de enfrentamento do vírus por parte do Governo Federal. Frente a isso, os Estados buscaram se 
organizar de diversas formas, buscando a continuidade dos processos de ensino e de aprendizagem (VIEIRA; RICCI, 2020).

Tratando especificamente da realidade do Estado de Minas Gerais, que é o foco deste estudo, a Secretaria de Educação (SEE/MG) institucionalizou o Regime Especial de Atividades Não Presenciais (REANP), por meio da Resolução SEE n 4310/2020. A referida normativa dispõe sobre as normas para a oferta das atividades não presenciais e institui o Regime Especial de Teletrabalho nas Escolas Estaduais da Rede Pública de Educação Básica e de Educação Profissional, de modo a garantir o cumprimento da carga horária mínima exigida (MINAS GERAIS, 2020).

De acordo, também, com a SEE/MG, foram desenvolvidas algumas ferramentas para auxiliar na implementação do referido regime. Uma dessas ferramentas foi o Plano de Estudo Tutorado, que buscou garantir a continuidade dos processos de ensino e de aprendizagem dos alunos no período em que as aulas presenciais estivessem suspensas, além de minimizar as desigualdades educacionais e o distanciamento do saber escolar durante o período de isolamento (MINAS GERAIS, 2020). Dessa forma, a partir de maio de 2020, foram elaborados e disponibilizados materiais pedagógicos para o acesso dos estudantes, os quais foram confeccionados em parceria entre a SEE/MG, a União Nacional dos Dirigentes Municipais de Educação (UNDIME) e professores da rede pública.

Dentro desse Regime, foram criadas frentes que, por meio de deferentes ferramentas, possibilitassem a interação com os componentes curriculares e a disponibilização dos conteúdos aos alunos. Além disso, estratégias de comunicação remota entre professores e alunos foram desenvolvidas. Nessa direção, três estratégias foram criadas, a saber: o Plano de Estudo Tutorado, o Programa de TV "Se Liga na Educação" e o Aplicativo Digital Conexão Escola.

De acordo com a SEE/MG, o Plano de Estudo Tutorado (PET) é formado por apostilas mensais que agregam um conjunto de atividades e orientação de estudos. Levam em consideração as habilidades e os objetos de aprendizagem de cada componente curricular preconizados para cada ano de escolaridade $\left(1^{\circ}\right.$ ao $9^{\circ}$ ano do Ensino Fundamental e $1^{\circ}$ ao $3^{\circ}$ ano do Ensino Médio), respeitando a carga horária mensal ofertada ao estudante. O conteúdo do PET foi construído em conformidade com o Currículo Referência de Minas Gerais (CRMG) e a Base Nacional Comum Curricular (MINAS GERAIS, 2020). Já o Programa de televisão "Se Liga na Educação" foi transmitido pela Rede Minas, de segunda a sexta-feira, das $7 \mathrm{~h}$ às 12h30min, sendo as sextas-feiras destinadas ao Exame Nacional do Ensino Médio (ENEM). No tocante ao aplicativo digital, disponibilizado gratuitamente na loja de aplicativos dos 
smartphones, trata-se de um aplicativo para celular denominado 'Conexão Escola', que se constitui como mais uma forma de acesso ao PET e às aulas da Rede Minas (MINAS GERAIS, 2020).

Para o registro das atividades, a Resolução supracitada apresenta, no Anexo 1, o Registro das Atividades do Plano de Estudos Tutorado e Cumprimento da Carga Horária. Tratase de um documento para que professores façam anotações e observações individuais dos estudantes. Além disso, segundo a SEE/MG, no site https://estudeemcasa.educacao.mg.gov.br/, professores, alunos e comunidade escolar podem esclarecer possíveis dúvidas em relação ao acesso aos materiais e às demais ferramentas e recursos (MINAS GERAIS, 2020). Esse foi o caminho encontrado pelo Estado para não paralisar totalmente o ensino e a aprendizagem dos estudantes da rede.

Desse modo, de acordo com Couto et al. (2020, p. 209), "professores e alunos matriculados em cursos antes presenciais, migraram para atividades educacionais em rede". Observa-se que, no grupo dos professores, aqueles que já se colocam como influenciadores digitais na docência fazem suas transmissões online por meio de canais, plataformas ou redes sociais digitais. Outros, foram estimulados e mobilizados a produzirem também as suas performances didáticas online (COUTO et al. 2020). Os autores explicam que os profissionais da educação, conectados, não só produzem e distribuem conteúdos, como também acompanham, orientam e estimulam seus alunos.

No entanto, as dificuldades nesse contexto são evidentes, principalmente para os professores que não detêm um conhecimento aprofundando acerca das tecnologias digitais. Esse novo formato de se trabalhar pedagogicamente trouxe estranheza tanto para os docentes, quantos para os discentes. O novo causa sentimento de algo estranho. Muitos se assustam com o nunca visto, com o nunca experienciado. Mesmo que um humano seja estudioso, que se esforce bastante em aprender, sempre poderá ser surpreendido pelo desconhecido e essa sensação é de estranhamento (BHABHA, 2010).

\section{CAMinhos PERCORRIDOS}

O relato aqui apresentado refere-se a uma pesquisa qualitativa com abordagem bibliográfica. Nesse sentido, foram analisados os Cadernos $\mathrm{n}^{\circ} 1$ dos Planos de Estudos Tutorados do Ensino Fundamental Regular - Anos Finais, apresentados pela Secretaria Estadual de Educação do Estado de Minas Gerais, que fazem parte do REANP. Conforme já referido, tais planos foram a alternativa para dar continuidade aos processos de ensino e de aprendizagem 
no período de suspensão das aulas presenciais na Rede, em decorrência da pandemia da COVID-19.

Para a análise descritiva, observaram-se os Cadernos $n^{\circ} 1$ do $6^{\circ}$ ao $9^{\circ}$ ano, buscando identificar aspectos que estivessem diretamente relacionados com Coronavírus, COVID-19 e pandemia. Convém referir que, nos PETs, as disciplinas foram organizadas em quatro semanas. Assim, para o presente estudo considerou-se a disciplina e a semana. Verificou-se, ainda, as unidades temáticas, o objeto de conhecimento, as habilidades e os conteúdos relacionados nos planos.

\section{Resultados E Discussão}

Inicialmente, evidenciou-se que os Cadernos que compõem o Plano de Estudos Tutorados da SEE/MG não trazem o tema Coronavírus com clareza. Nesse sentido, acredita-se que esses materiais pedagógicos deveriam ter abordado a temática de forma mais enfática, uma vez que é papel da escola instruir os estudantes e dar possibilidade de (re)construção do conhecimento.

Da mesma forma, observou-se que não houve uma abordagem desse assunto na disciplina Ciências, área que tem ligação direta com a temática. Não que necessariamente o tema deveria ser exclusivo para esta disciplina, mas acredita-se que, tendo em vista da sua proximidade com conteúdos da área, a possibilidade de se estabelecer relações entre o tema e a disciplina é maior. Salienta-se, ainda, a possibilidade de se fazer conexão entre as diversas disciplinas, o que se configura como uma proposta pedagógica relevante nos processos educacionais.

Os resultados da análise realizada em cada um dos Cadernos do Ensino Fundamental Regular - Anos Finais mostraram o número reduzido de atividades que ressaltavam o tema Coronavírus. Referindo-se especificamente aos planos de ensino do $6^{\circ}$ ano, o tema foi abordado em três componentes curriculares: Língua Portuguesa, Matemática e Língua Inglesa. A descrição e análise das atividades propostas nesta série é feita na sequência.

Analisando o componente de Língua Portuguesa, na quarta semana, foi abordada a temática gênero textual folheto/panfleto. Objeto de conhecimento foi a produção e edição de textos publicitários que tratassem dos cuidados para não contrair o vírus da COVID-19 (Figura $1)$. 
Figura 1 - Componente curricular de Língua Portuguesa - PET do Estado de Minas Gerais

\section{ATIVIDADES}

ATIVIDADE 1- Agora é sua vez.

Seja criativo e crie uma campanha publicitária sobre os cuidados para não pegar a Covid19 , "coronavírus".

- Não se esqueça de checar:

- Oual o público-alvo;

- Mensagem;

- Informação (ões) indispensável (is):

- Imagem (ns) de acordo com a mensagem. Cor predominante.

- Nảo se esqueça de usar a pontuação corretamente.

ATIVIDADE 2 - Faça a revisão da sua produçāo. Além de focar nos erros gramaticais, por exemplo, na ortografia das palavras, na concordåncia verbal e nominal ou na pontuaçảo, nảo se esqueça de verificar: 0 texto está adequado ao público-alvo? Aborda a temática de modo satisfatório? Os aspectos visuais produzem o efeito pretendido? É o momento, portanto, de eliminar ou acrescentar trechos, substituir, inverter, verificar se o léxico está adequado.

BOM TRABALHO!

Fonte: Plano de Estudo Tutorado No $1-$ SEE/MG (2020).

Percebeu-se que esta questão aborda o tema Coronavírus de forma pontual, pois trazia a possibilidade de os estudantes pensarem nas orientações oficiais necessárias para prevenção e controle da COVID-19 e também na ideia de coletividade, uma vez que deveriam elaborar um texto informativo com a temática.

O componente curricular de Matemática trouxe o tema na terceira semana, quando foi abordado o objeto de conhecimento Sistema de Números Decimais, relacionado com leitura, escrita e comparação de números naturais e racionais. As habilidades definidas para a unidade temática foram o reconhecimento do sistema de numeração e comparação com outros sistemas. A questão utilizava-se de recurso imagético (charge) para elucidar o estabelecimento de um pensamento crítico pelo estudante (Figura 2). 
Figura 2 - Atividade de Matemática utilizando charge nas escolas estaduais de Minas Gerais

\begin{abstract}
ATIVIDADE 2 - Leia a Charge do Amarildo: 0 coronavirus e a aula de Matemática. Pense um pouco sobre ela.
\end{abstract}

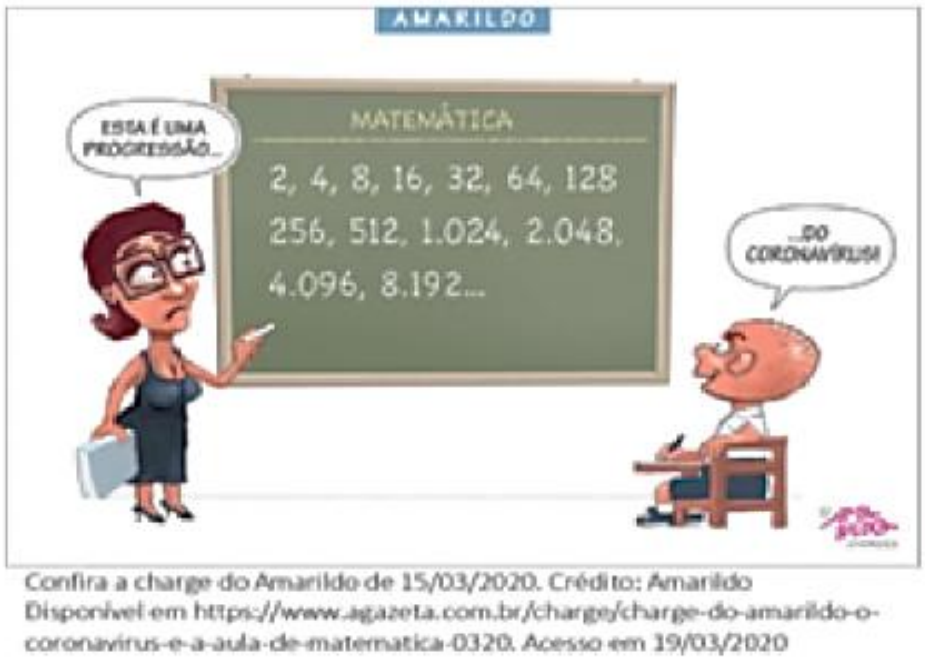

Observe os números 1024, 2048, 4096, 0320 e 2020.

a) 0 que o zero representa em cada uma das posições?

Fonte: Plano de Estudo Tutorado No 1 - SEE/MG (2020).

A questão mostrada na Figura 2, a princípio, é bem instigadora, pois propõe uma reflexão crítica acerca da relação da Matemática com o Coronavírus por meio de uma charge. Contudo, logo direciona o olhar do aluno para um conteúdo de matemática, sem fazer nenhuma outra exploração adicional do tema. Pelo fato de se tratar de estudo remoto, acredita-se que poderiam ter enfatizados mais aspectos importantes para o momento atual. Pensa-se que se fosse em sala de aula, talvez o professor tivesse a possibilidade de explorar a questão para o aprofundamento e levar o estudante a entender a aplicabilidade da Matemática no cotidiano.

Já em relação ao plano tutorado do componente de Língua Inglesa, a unidade temática da segunda semana foi centrada nas estratégias de leitura e o objeto de conhecimento voltou-se para a leitura e a compreensão textual. As habilidades envolvidas foram a formulação de hipóteses acerca da finalidade do texto, localização de informações e identificação de palavras cognatas. A questão apresenta um pequeno texto explicativo dos impactos do Coronavírus (Figura 3), a partir do qual trabalha a leitura e o estudo de pronome. Contudo, o estudante não é instigado a fazer grandes reflexões sobre a temática da COVID-19. 
Figura 3 - Questão do Componente de língua inglesa nas escolas estaduais de Minas Gerais

ATIVIDADE 6 - Coronavirus is spreading around the world. It affects many people and businesses. It affects sports, too. A frase diz que o Coronavirus está se espalhando pelo mundo e que afeta muitas pessoas e negócios e afeta os esportes, também. 0 pronome it que inicia a segunda frase se refere à qual palavra?

ATIVIDADE 7 - Numere as ideias do texto de acordo com a sequência ou ordem como as informações aparecem no texto:

( ) O Presidente do Comitê Olimpico está esperançoso.

( ) 0 Coronavirus está se espalhando pelo mundo.

( ) 0 Coronavírus pode afetar os Jogos Olímpicos também.

( ) Os Jogos Olímpicos começam no verão de 2020.

Fonte: Plano de Estudo Tutorado $\mathrm{N}^{\mathrm{o}} 1$ - SEE/MG (2020).

Descrita a análise do plano do $6^{\circ}$ ano do Ensino Fundamental regular, passou-se, então, ao plano do $7^{\circ}$ ano. Nessa turma, o tema foi abordado no Caderno de Língua Portuguesa e no Caderno de Língua Inglesa.

No plano de Língua Portuguesa, não está explícita a unidade temática da primeira semana, mas é possível entender que se trata de gêneros textuais, mais precisamente, do estudo das características da notícia. O objeto de conhecimento foi a construção composicional e o estilo de uma notícia. A atividade trouxe três blocos de habilidades a serem exploradas pelos estudantes, relacionadas com a escrita da notícia, com o foco nas características do texto digital. Os conteúdos relacionavam-se ao tema, ao fato e ao assunto da notícia, finalidade do texto, morfologia verbal e o uso do link. Quanto às atividades, observou-se a apresentação de noticiários com diversas informações da COVID-19 (Figuras 4 e 5). 
Figura 4 - Atividade de leitura de texto jornalístico nas escolas estaduais de Minas Gerais

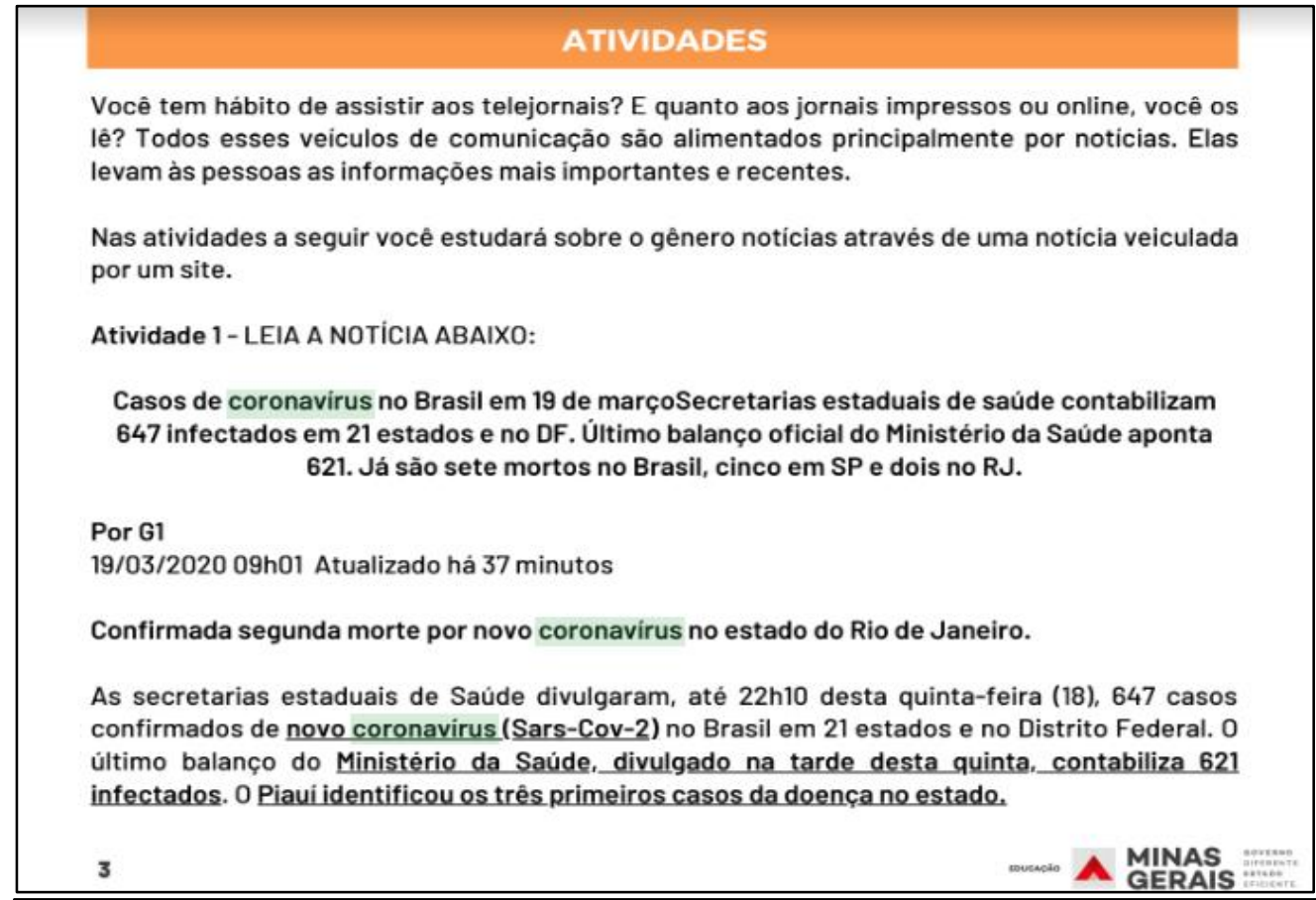

Duas mortes foram confirmadas no Rio de Janeire nesta quinta-feira pela secretaria de Saúde. Em Säo Paulo, foram reglstradas cinco mortes até o momento pelo governo estadual, o que eleva ao total de óbitos no Brasil para sete. 0 Ministério da Saúde registrou quatro mortes em SP e duas no RJ.

Também nesta quinta, a secretaria de Saúde de Alagoas atualizou o número de 1 para 4 casos. O Rio Grande de Sul registrou mais casos confirmados e agora registra 37 infectados. A secretaria de saúde do Paraná infermeu que o estado registra 23 cases. Em São Paulo, o número de casos confirmados do novo coronavinus aumentou de 240 para 286.Fonte: Secretarias estaduais da Saúde e Ministério da Saúde

\section{Transmissảo comunitária}

De acordo com o ministério. há transmissăo comunitária em algumas áreas do pais. A pasta clta dois estados, trés capitais e uma regiào de um estado no Sul. A transmissào comunitária ou sustentada é aquela quando nào é possivel rastrear qual a origem da infecçào, Indicando que o virus circula entre pessoas que não viajaram ou tiveram contato com quem esteve no exterior. A transmissāo comunitária está configurada nos estados de Sào Paulo e de Pernambuco. Alèm disso. ocorre isoladamente em três capitais: Rio de Janeiro. Belo Horizonte e Porto Alegre (alèm das capitais de SP e PE, já incluidas acimal

Por fim, a pasta também considera o mesmo status apenas para o sul de Santa Catarina, mais especificamente a regijo da cidade de Tubarßo. A declaraça náo vale para todo o estado.

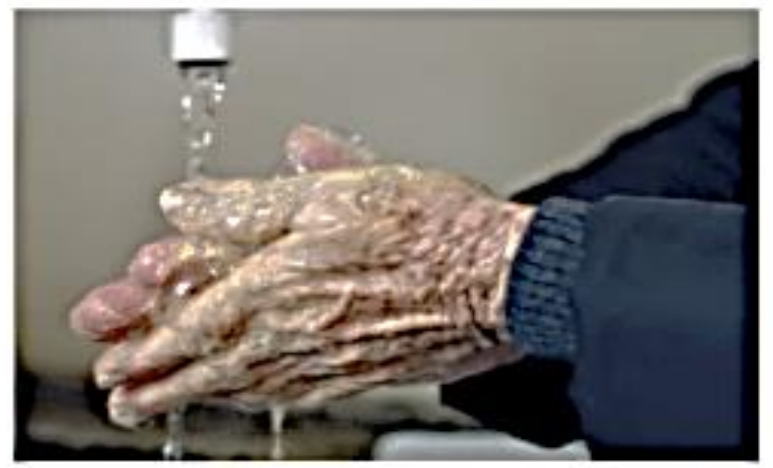

Lavar as màos com àgua e sabåo ê a methor maneira para prevenir o coronavirus Foto: Carlos Pot.

Fonte: Plano de Estudo Tutorado $\mathrm{N}^{\circ} 1-\mathrm{SEE} / \mathrm{MG}$ (2020). 
Figura 5 - Texto de notícias relacionadas ao Coronavírus

Situação no mundo

De acordo com informaçōes da Orģanização Mundial da Saùde (atualizadas às $16 \mathrm{~h} 40$ de quartafeiral, houve 207.855 casos confirmados e mais de 9.000 mortes per Covid-19 em 166 paises e territórios.

0 balanço apontou que cerca de $34 \%$ das mortes estão concentradas em Hubei, provincia chinesa onde se iniciou o surto: là, foram ao menos 3.130 vitimas fatais. A ltália aparece como o segundo pais com mais mortes por novo coronavirus, são $2.978,32 \%$ de todas as mortes no mundo.

Autoridades da China reportam 34 novos casos de coronavirus todos vindos de fora do pais

A China anunciou nesta quinta-feira que, pela 11 vez desde o inicio do surto, nảo registrou qualquer novo caso de transmissào local do novo coronavirus, mas teve 34 novos casos de infectados que vieram do exterior.

Também nesta quinta. os governos da Austrália e da Nova Zelăndia anunciaram a suspensăo da entrada de pessoas não residentes no pais, para reforçar as medidas destinadas a conter a propagaçäo da pandemia de Covid-19.

Até o momento, os paises não determinaram o fechamento das escolas nem adotaram medidas de confinamento. A Austrälia registra 642 casos confirmados do novo coronavirus e a Nova Zslándia, 28.

\section{Brasil contraria OMS e só faz testes nos casos graves}

O secretário-executivo do Ministério da Saúde, Joào Gabbardo, afirmou que nào mudaráa agora o critério adotado na fase de mitigaçăo, e só as pessoas com casos graves serăo testadas.

A Organizaçẫo Mundial da Saúde (OMS) recomendou, na última sexta-feira (13) que 05 paises apliquem testes em massa para descobrir quem està infectado e isolar esses pacientes para "achatar a curva" da disseminaçăo da doença Covid-19.

0 governo federal, que disse ter comprado kits da Fiocruz para 30 mil testes nos laboratórios públicos, disse que o objetivo da medida é economizar testes para as pessoas com complicaçỏes.

\section{HORA DE EXERCITAR}

Atividade 2 - Releia o primeiro parágrafo da noticia e responda às perguntas.

a) Qual foi o acontecimento?

Fonte: Plano de Estudo Tutorado Nº $1-$ SEE/MG (2020).

Os textos mostrados na Figura 4 seguem uma sequência, apesar de serem fragmentos de notícias. Fazem destaque à transmissão comunitária do Coronavírus. Há uma imagem legendada que favorece que o estudante pense na prevenção contra o vírus. Entretanto, entendeu-se que a proposta poderia tornar difícil a compreensão para o aluno com dificuldade 
de leitura e, consequentemente, a assimilação da informação. Talvez se a situação fosse apresentada numa tirinha, poderia ser melhor compreendida.

Os textos da Figura 5 também reportam informações acerca do Coronavírus. Também são fragmentos de notícias, todavia, o foco foi a construção textual. Indagaram-se as características principais do texto jornalístico - o que aconteceu, onde aconteceu e quando aconteceu - e foi solicitado que o estudante fizesse a relação da legenda com a foto apresentada na notícia. Esta última situação aponta uma das formas de prevenção do vírus. Neste caso, entende-se que poderia ter ocorrido uma exploração de modo intensificado, ou seja, frisando a eficiência dos testes, uma vez que os textos tratam de informações diretas da COVID-19.

Na semana 2, o plano de Língua Portuguesa do $7^{\circ}$ ano continuou com o estudo do gênero textual notícia, o mesmo objeto de conhecimento abordado na semana 1. Todavia, as habilidades são a identificação do fato central da notícia, as circunstâncias e as possibilidades da sua decorrência, além de busca da percepção e análise dos recursos utilizados no gênero jornalístico. Em relação aos conteúdos, foram trabalhados os tempos verbais e a linguagem coloquial. Na atividade desta semana, o tema Coronavírus surgiu como suporte textual para o estudo do gênero notícia, e focou na expressão 'transmissão comunitária'. No entanto, não foram referidos mais detalhes sobre o assunto, de modo que a questão focou, apenas, no conteúdo de Língua Portuguesa em si (Figura 6). 
Figura 6 - Atividade 1 da semana 2 de Língua Portuguesa do $7^{\circ}$ ano nas escolas estaduais de Minas Gerais

\section{ATIVIDADES}

Atividade 1- Releia o trecho da noticia.

"A China anunciou nesta quinta-feira que. pela $1 "$ vez desde o inicio do surto, não registrou qualquer nove caso de transmissajo local de novo coronavirus, mas teve 34 novos casos de infectados que vieram do exterior."

a) Oual o fato apresentado nesse trecho?

b) De acordo com a noticia o que significa "transmissào comunitária"?

c) A noticia estava disponivel em uma página da internet. Que recursos não seriam possiveis na versäo impressa da noticla?

Fonte: Plano de Estudo Tutorado No1-SEE/MG (2020).

Continuando com a observação das atividades da semana 2, notou-se que um pequeno texto anunciava a atividade 2 (Figura 7 ) se tratava de um texto que trazia o tema Coronavírus, contudo, mais uma vez, apenas como suporte textual. 
Figura 7 - Atividade 2 da semana 2 de Língua Portuguesa do $7^{\circ}$ ano

Atividade 2 - Observe o trecho "os países apliquem testes em massa para descobrir quem está infectado e isolar esses pacientes para achatar a curva" da disseminação da doença Covid-19".

Explique o emprego das aspas no trecho acima.

Atividade 3 - Qual o tempo verbal foi empregado? Que efeito de sentido ele provocou no texto?

Atividade 4 - Releia a noticia e observe que os adjetivos são pouco utilizados. Por quê?

Atividade 5 - Qual classe gramatical predomina em uma notícia?

Fonte: Plano de Estudo Tutorado No $1-$ SEE/MG (2020).

Nesta questão, o texto fala sobre os testes em massa da COVID-19 e o achatamento da curva de transmissão. Estes são aspectos importantes da pandemia, mas não houve maiores direcionamentos para tais aspectos, como uma explicação do significado de achatamento e curva de transmissão. $\mathrm{O}$ foco estabeleceu-se sobre situações gramaticais.

$\mathrm{Na}$ semana 3 do plano dessa disciplina, foi dado continuidade ao estudo do gênero textual notícia. Para esta semana, o objeto de estudo trouxe a relação do texto com o contexto e estratégias de produção de textos. Os conteúdos foram os mesmos referidos na semana 2, com o acréscimo do uso do link e da produção de hipertextos. Nesta semana, verificou-se uma atividade com a temática da COVID-19: foi proposta a criação de uma notícia reportando dados atualizados da propagação no Brasil (Figura 8). Desse modo, para a elaboração da notícia, necessariamente o aluno deveria ir em busca de informações científicas acerca da pandemia. 
Figura 8 - Proposta de produção de texto focando a propagação da Covid-19

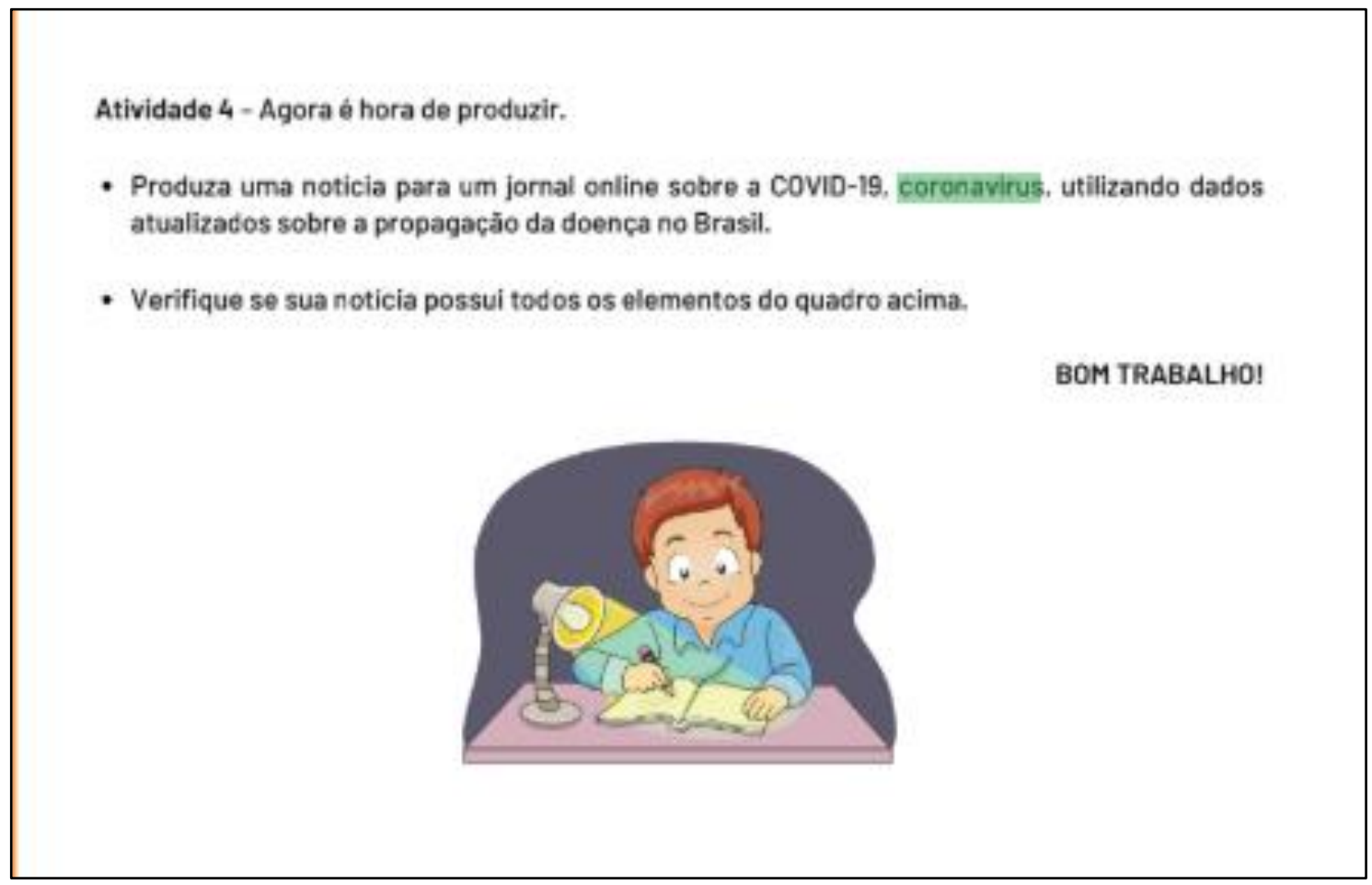

Fonte: Plano de Estudo Tutorado No $1-$ SEE/MG (2020).

Esta atividade da Figura 8 deu possibilidade de autonomia para busca e seleção de informações que, de certa forma, poderiam auxiliar no aprendizado e no desenvolvimento do indivíduo. Pensa-se que, nesse caso, o estudante poderia fazer associações daquilo que já se sabe com novas informações e formalizar nova aprendizagem. Segundo Ausubel (2003), na aprendizagem escolar não se pode lidar tanto com a transferência no sentido literal do termo, mas com a influência que os conhecimentos anteriores podem ter sobre a nova aprendizagem.

Por fim, o plano do $7^{\circ}$ ano de Língua Inglesa teve como unidade temática as estratégias de leitura. $\mathrm{O}$ objeto de conhecimento se referia às estratégias de compreensão de textos e as habilidades foram no sentido de mobilizar conhecimentos prévios para compreender textos e identificação de contextos, finalidade e assunto. A atividade sugeria assistir a um vídeo em inglês intitulado Coronavírus: como podemos nos prevenir. Apesar de o vídeo ser em inglês, a atividade levava a pensar no tema, e direcionava para frases comumente proferidas em tempos de pandemia, como "Stay at Home", que se traduz em "Fique em casa", "Fake News", traduzida por "Falsa Notícia", além de outras (Figura 9). 
Figura 9 - Atividade de Língua Inglesa do plano do $7^{\circ}$ ano nas escolas estaduais de Minas Gerais

\title{
ATIVIDADES
}

\begin{abstract}
Caro estudante!
É bom que nos dias atuais temos muitas possibilidades de leitura. A biblioteca não é mais o único lugar para se ler. $\mathbf{O}$ celular conectado à Internet é um grande recurso para a leitura, onde encontramos uma fonte rica de informações. 0 importante é prestar atenção em tudo, no som e nas imagens que nos revelam muito do que quer ser transmitido ou comunicado.
\end{abstract}

1- Assista ao seguinte video da BBC inglês: Clique no seguinte link para assistir o video https://www.bbc.com/news/av/health-51652874/coronavirus-how-to-self-isolate

2- Responda às seguintes questões:

$O$ vídeo da $B B C$ é apresentado por um homem, um correspondente médico, qual o seu nome?

\section{3- De que trata o vídeo?}

4- Segundo o video, as pessoas que encomendarem alguma coisa via Internet, onde o entregador deve deixá-las?

7- As orientações são em número de 5. Numere de acordo com a sequência em que aparecem no video:

( ) ORDER IN

( ) STAY AT HOME

( ) TAKE CARE WITH WASTE

( ) SEPARETE YOURSELF

( ) CALL AHEAD

8. Qual a orientação considera mais importante no combate ao virus de acordo com sua opinião?

Fonte: Plano de Estudo Tutorado No $1-\mathrm{SEE} / \mathrm{MG}$ (2020)

$\mathrm{Na}$ atividade apresentada na figura 9, observou-se uma abordagem direta em relação ao Coronavírus, de modo que o aluno foi indagado acerca da orientação que ele considerada mais importante no combate ao vírus. A questão foi uma possibilidade de reflexão crítica acerca do tema e oportunizou trazer à tona o conhecimento prévio dos estudantes.

Passando-se para a análise do $8^{\circ}$ ano, observou-se que o tema em questão foi abordado no plano de Ciências da quarta semana. Nesse planejamento, a unidade temática abordava vida e evolução, tendo como objeto de conhecimento as funções de nutrição. As habilidades relacionavam-se à identificação das principais doenças causadas por vírus, bactérias, protozoários e fungos. Os conteúdos desenvolvidos foram o estudo do sistema respiratório, trocas gasosas, microrganismos e saúde pública e Coronavírus (COVID-19). 
Nessa atividade foram apresentadas informações acerca da COVID-19. Além disso, sugeriram-se vídeos da plataforma de vídeo Youtube que abordam a prevenção da doença. Cabe referir que as informações foram apresentadas de maneira simples, o que possibilitou uma fácil compreensão por parte dos estudantes.

Figura 10 - Ênfase de informações acerca do Coronavírus nas escolas estaduais de Minas Gerais

\section{DESENVOLVENDO O TEMA:}

São muitas as doenças que afetam o sistema respiratório, daremos ênfase à CoviD-19, provocada pelo coronavírus, que chamou atenção do mundo já na primeira semana de 2020 pelo alto número de casos , já considerada Pandemia.

O termo "Pandemia" corresponde a uma doença que afeta um grande número de pessoas em diversas regiōes do globo simultaneamente.

Depois que o COVID-19 surgiu em Wuhan, na China, o virus se espalhou rapidamente por outros paises e regiões, o que aumentou as chances de a OMS declarar uma pandemia.

Assistam ao video "Como Combater o Coronavirus", disponivel no Youtube, que pode ser acessado pelo link: https://www. youtube.com/watch? $y=F f 3 g A 07 E 4 v c \&$ feature=emb_rel_end $O$ video aborda os cuidados que devemos ter para não sermos contaminados pelo virus (COVID-19).

\section{Sobre o Coronavirus}

Pertence a uma familia de virus que causam infecçōes respiratórias. O novo agente do coronavirus foi descoberto em 31/12/2019 após casos registrados na China. Recebeu o nome de COVID-19.

Quais são os sintomas?

Além dos sintomas típicos da gripe - como febre, tosse, dor muscular e cansaço, o coronavírus pode afetar o sistema respiratório da vítima, causando pneumonia e podendo matar. As pessoas mais suscetiveis às consequências graves do vírus são idosos e pessoas com condições preexistentes.

\section{Como é a transmissão?}

O coronavirus é transmitido da mesma forma que uma gripe comum. Isso significa que a doença é transmitida pelo contato com secreçōes de pessoas contaminadas: gotículas de saliva, espirro, tosse, toque ou aperto de mão seguido de contato com boca, nariz e olhos.

Ouais são os sintomas?

Além dos sintomas típicos da gripe - como febre, tosse, dor muscular e cansaço, o coronavirus pode afetar o sistema respiratório da vitima, causando pneumonia e podendo matar. As pessoas mais suscetiveis às consequências graves do vírus sāo idosos e pessoas com condiçōes preexistentes.

\section{Como é a transmissão?}

o coronavirus é transmitido da mesma forma que uma gripe comum. Isso significa que a doenç é transmitida pelo contato com secreçōes de pessoas contaminadas: goticulas de saliva. espirro, tosse, toque ou aperto de mão seguido de contato com boca, nariz e olhos.

\begin{tabular}{|c|c|c|}
\hline GOTICULAS RESPIRATÓRIAS & $\begin{array}{l}\text { CONTATO PROXIMO } \\
\text { APROXIMADAMENTO } 2 \\
\text { METROS, COM ALGUEM } \\
\text { COM SINTOMAS }\end{array}$ & $\begin{array}{l}\text { CONTATO DIRETO COM AS } \\
\text { SECREÇOES SEM PROTEÇĀO }\end{array}$ \\
\hline
\end{tabular}

\section{Como é feita a prevenção?}

Assista ao video "Com Prevenir contra o Coronavirus", disponivel no Youtube, podendo ser acessado pelo link: https: / www youtube.com/watch? $\mathrm{v}=5 \mathrm{rLG} / \mathrm{Ls} / \mathrm{gl}$

\section{Aprofundando seus conhecimentos:}

Combate 0 alarde $e$ as fake news: Doencas virais e epidemias sempre causam alarde na populaçāo. A confirmação do novo coronavírus foi também usada para disseminação de noticias falsas (fake news). Constantemente são divulgadas informaçōes falsas (Fake news) sobre o Novo Coronavirus, que vão desde teorias sobre o surgimento do virus até receitas milagrosas, todas sem o menor embasamento cientifico. O Ministério da Saúde desmentiu diversos boatos que começaram a circular na internet sobre o coronavirus. As fake news causam pânico na populaçāo e atrapalham os trabalhos de investigação das autoridades competentes, sendo imprescindivel combatê-las.

Fonte: Plano de Estudo Tutorado No 1 - SEE/MG (2020). 
A segunda parte da atividade relaciona o tema Coronavírus com as fake news, direcionando para reflexão do que é fato em relação ao assunto. Na sequência foram sugeridos links para a busca de mais informações sobre o assunto.

Figura 11 - Atividade do plano de ciências do $8^{\circ}$ ano nas escolas estaduais de Minas Gerais

\section{ATIVIDADES}

\section{ATIVIDADE 1 - JOGO: FATO OU FAKE?}

Objetivo: Permitir que os estudantes compreendam e analisem corretamente as informações que recebem nas redes sociais sobre o Novo Coronavirus, por meio de um jogo de interpretação de texto e discussão critica sobre fake news. Sugerimos que utilizem as informações já checadas pelo Ministério da Saúde para propor aos estudantes o jogo Fato ou Fake. Você pode utilizar as questões impressas, projetá-las ou utilizar uma plataforma digital para esta atividade.

Informações sobre o Novo Coronavirus:

- Toda as compras feitas pela internet em sites chineses estão contaminadas.

- Sintomas do Novo Coronavírus: febre, tosse, falta de ar e nos casos mais graves: evolução para uma pneumonia ou síndrome respiratória aguda grave ou insuficiência renal.

- Histórico de viagem para área com transmissão local, de acordo com a OMS, nos últimos 14 dias anteriores ao aparecimento dos sinais ou sintomas.

- Histórico de contato próximo de caso suspeito para o coronavirus nos últimos 14 dias anteriores ao aparecimento dos sinais ou sintomas.

- Contato próximo de caso confirmado de coronavirus em laboratório, nos últimos 14 dias anteriores ao aparecimento dos sinais ou sintomas.

- Chá de abacate com hortelã evita a contaminação pelo Coronavírus.

- Cientistas indianos acabaram de encontrar inserçōes semelhantes ao virus HIV (AIDS) no Coronavirus que não são encontradas em nenhum outro coronavírus do passado. Eles sugerem a possibilidade de que esse virus chinês tenha sido criado em laboratório.

- Finalizado o jogo, reflita sobre como a confiabilidade das informações é colocada à prova em consequência da rápida propagação das fakes news.

ATIVIDADE 2 - Aplicando seus conhecimentos, RESPONDA:

1. Quais as consequências das fake news no cotidiano?

2. Por que é importante checar as informações?

3. Como verificar se uma informação é falsa ou verdadeira?

\section{ALGUMAS DICAS PARA COMBATER AS FAKE NEWS:}

- Antes de repassar uma informação verifique detalhes do website:

- Leia a seção "Sobre Nós", os sites confiáveis têm informaçōes de contato dos autores e confira os perfis nas redes sociais:

- Veja sempre a fonte primária da noticia;

- Procure confirmar as informaçōes em outras mídias;

- Confira sempre a data e a localização das publicaçōes:

- Não compartilhe o conteúdo sem consultar previamente sua veracidade.

Saiba mais ..

- https://www.infoescola.com/fisiologia/respiracao/

- http://www.saude.sp.gov.br/resources/cve-centro-de-vigilancia-epidemiologica/areas-devigilancia/doencas-de-transmissao-respiratoria/coronavirus.html

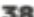

Fonte: Plano de Estudo Tutorado No 1- SEE/MG (2020).

$\mathrm{Na}$ estruturação desse plano, houve uma sinalização para a ênfase na pandemia da COVID-19. No entanto, ao analisar a proposta, verificou-se que as atividades, apesar de salientarem o assunto, não o exploraram, de forma enfática, como é sugerido. Considerando que o conteúdo citado é o sistema respiratório, poderia ter havido uma abordagem mais 
aprofundada em relação aos problemas respiratórios e a COVID-19. Além disso, por se tratar da disciplina Ciências, talvez houvesse maior possibilidade de trabalhar essas temáticas tão colocada em evidência no período de pandemia que vivemos.

O plano do $9^{\circ}$ ano trouxe o tema COVID-19 nas atividades propostas em Matemática e Geografia. Na disciplina Matemática, na semana 4, foi trabalhada a unidade temática grandezas e medidas. $\mathrm{O}$ objeto de conhecimento foram as unidades de medidas utilizadas na informática. As habilidades da atividade eram reconhecer e empregar unidades usadas para expressar medidas muito grandes ou muito pequenas, como a distância entre planetas e tamanhos de vírus ou células e capacidade de armazenamento de computadores, dentre outros.

No que tange às atividades de Matemática, observou-se uma charge que fazia uma conexão crítica entre o uso de máscara para proteção contra o Coronavírus e a propagação de fake news (Figura 12).

Figura 12 - Atividade de matemática do $9^{\circ}$ ano nas escolas estaduais de Minas Gerais

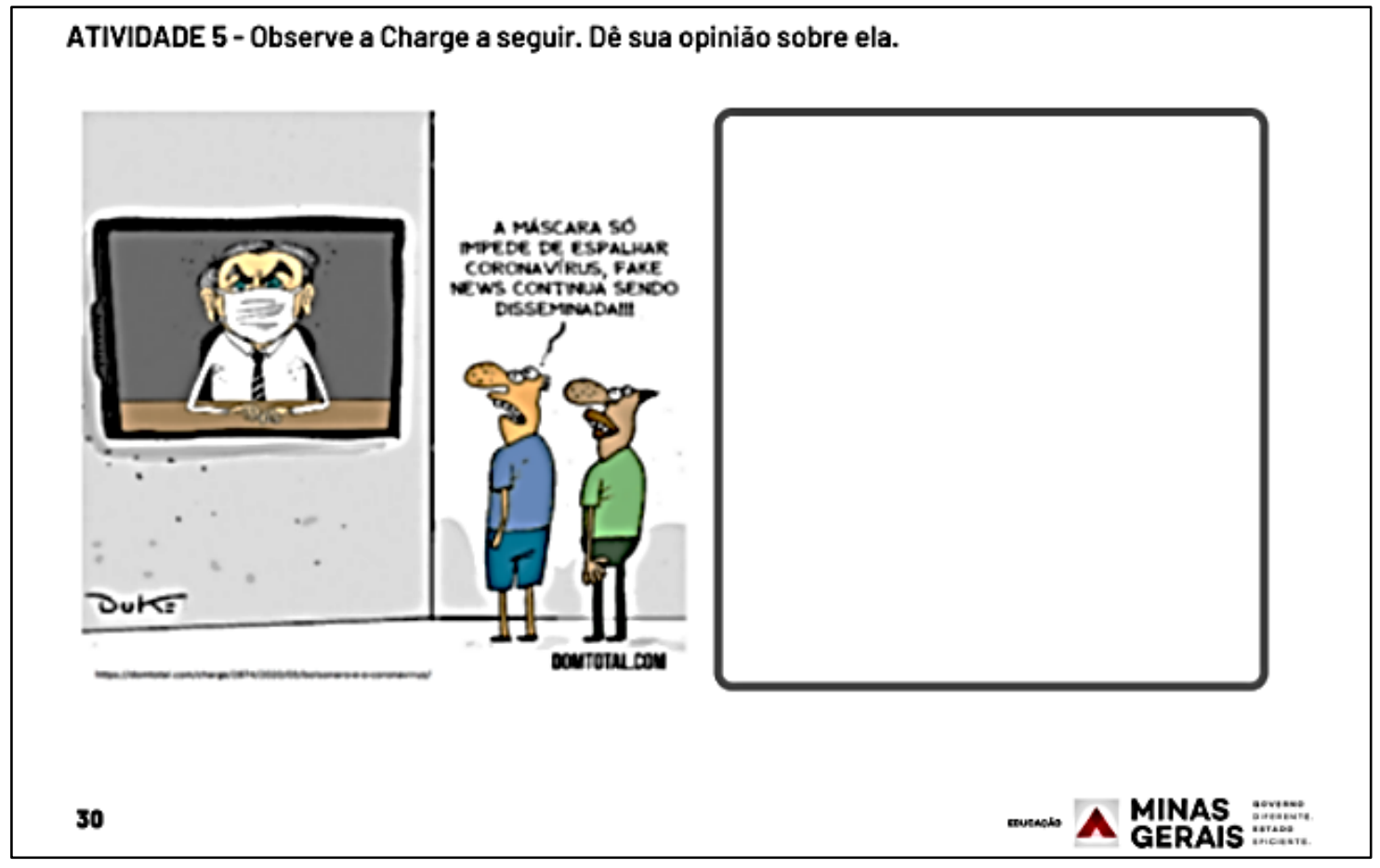

Fonte: Plano de Estudo Tutorado No 1- SEE/MG (2020).

$\mathrm{Na}$ atividade referida na Figura 12, foi solicitada a opinião do estudante. Dessa forma, o aluno teve a oportunidade de realizar uma reflexão crítica sobre a temática em questão e expressá-la. Acredita-se que, pelo fato de se tratar de um estudo remoto, em que não há a mediação direta do professor, caberia um anunciado mais instigante na questão, a fim estimular o pensamento crítico, já que não está associada ao conteúdo de matemática em si. Caso fosse trabalhada uma questão nesse formato em sala de aula presencial, certamente haveria 
intervenções por parte do professor que instigaria discussão entre os estudantes. Conforme Machado (2001), para se apropriar do saber acadêmico, cada estudante traça, individualmente, um caminho que é mediado pelo professor e pelos colegas.

$\mathrm{Na}$ atividade aludida na Figura 13, a questão de número 6 menciona o tema Coronavírus, estabelecendo relação com fake news. Notou-se que a questão também oportuniza a expressão da autonomia e da criticidade, todavia, não há referência ao conteúdo proposto na unidade de estudo.

Figura 13 - Atividades com foco na utilização da máscara preventiva ao Coronavírus

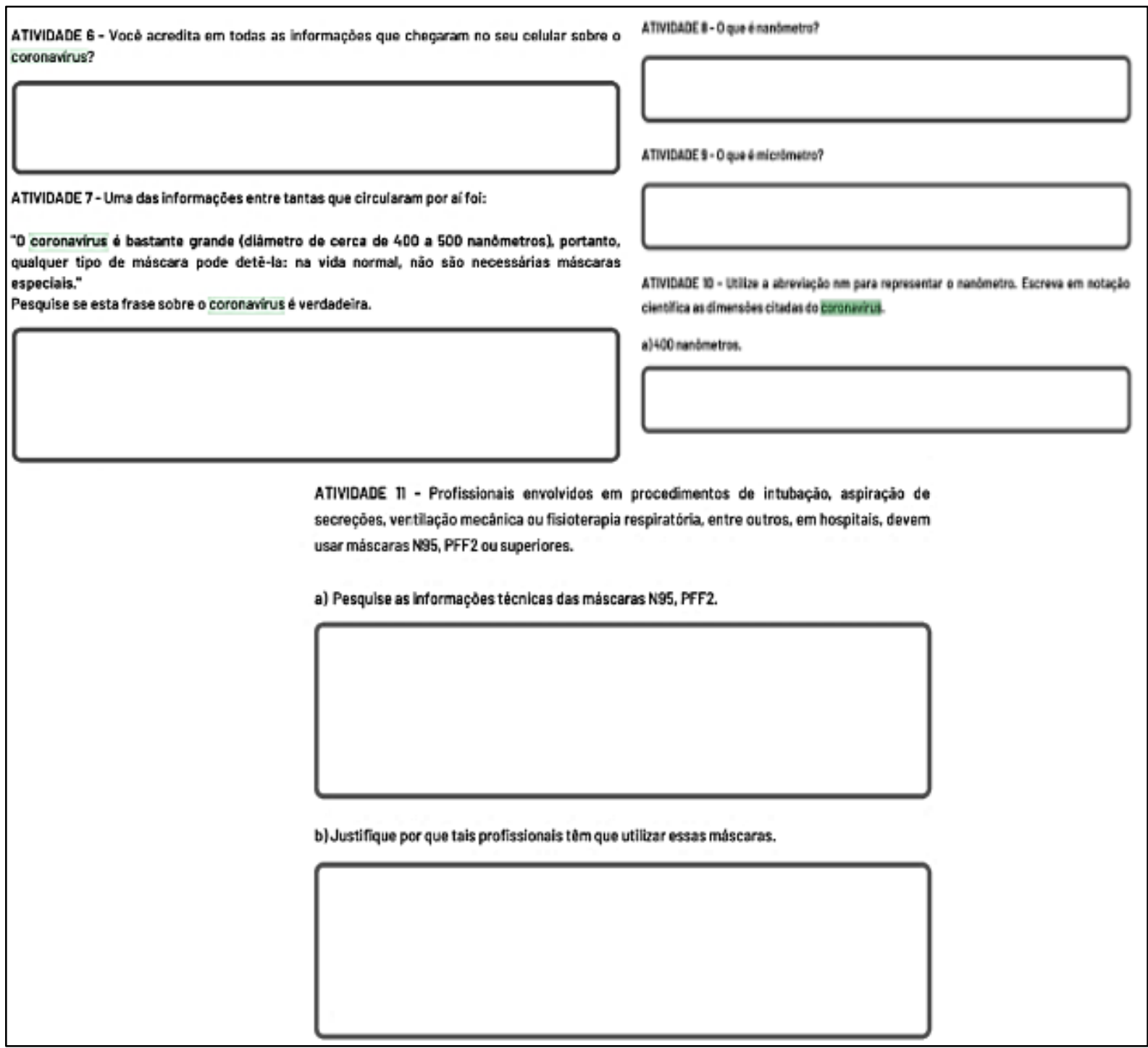

Fonte: Plano de Estudo Tutorado No 1- SEE/MG (2020).

As atividades apresentadas acima direcionam para pensar no tamanho do vírus e possibilitam ao estudante pensar nos diferentes tipos de máscaras associadas à prevenção ao Coronavírus. Trazem a Matemática vinculada à questão das medidas, levando a analogias e conclusões. Além disso, estas atividades ainda possibilitam ao estudante pensar nos diversos 
profissionais da saúde que se envolvem na prevenção, tratamento e controle da pandemia. Analisando, são atividades abrangentes, mas que necessitam da mediação do professor.

A outra disciplina do $9^{\circ}$ ano com o tema em voga foi Geografia. Na semana 1 , a disciplina teve como unidade temática o sujeito e seu lugar no mundo. O objeto de conhecimento abordado foram as corporações e organizações internacionais. Como habilidades, visou identificar e analisar a atuação das corporações internacionais e organizações econômicas mundiais na vida da população em relação ao consumo, à cultura e à mobilidade. Como conteúdo, a proposta explorou a globalização e a mundialização, as corporações internacionais, as organizações internacionais (ONU), a organização mundial do comércio, a o Organização Mundial da Saúde (OMS), dentre outras.

A disciplina trouxe uma questão que evidencia o tema por meio da apresentação da queda da bolsa de valores relacionada ao Coronavírus (Figura 14). Certamente, essa atividade teria potencial de ser explorada mais intensamente, caso não fosse desenvolvida na forma remota. Acredita-se que muitos alunos, mesmo sendo do $9^{\circ}$ ano, ainda não têm uma concepção do significado da bolsa de valores nas relações econômicas nacionais e internacionais. Outro aspecto observado é que talvez fosse interessante ressaltar a ação da OMS, mencionada no conteúdo da proposta, na orientação para controle e prevenção da pandemia da COVID-19.

Figura 14 - Atividade de Geografia semana 1

\begin{abstract}
a) Procure nas etiquetas do seu vestuário, ou em equipamentos eletrônicos na sua residência onde foram produzidos pelo menos 6 produtos. Sinalize no mapa múndi os paises produtores da mercadoria. b) Pesquise onde estão as sedes das empresas pesquisadas e também localize no mapa. c) Crie uma legenda para os paises produtores e outra para os paises sedes das empresas. d) Crie um titulo para o mapa.
\end{abstract}

ATIVIDADE 2- A partir do seu mapa, escreva um pequeno parágrafo explicando como estão distribuidas as empresas transnacionais. Lembre-se de utilizar na sua resposta argumentos relacionados à divisão do mundo em paises ricos e pobres.

ATIVIDADE 3 - Leia a manchete.

Coronavírus: quedas na bolsa de valores colocam investidores na corda bamba

0

a) Explique como a noticia está diretamente associada ao fenômeno da globalização e da mundialização.

Fonte: Plano de Estudo Tutorado No 1- SEE/MG (2020).

$\mathrm{Na}$ análise, percebe-se que na disciplina História o tema não foi considerado. Haveria possibilidade de trazer os eventos passados de pandemia, a partir dos quais pudessem ser feitas analogias e associações. Nota-se que, de modo holístico, as atividades que ressaltam o tema 
Coronavírus não consideraram de forma firme a importância da pandemia, uma vez que não enfatizaram a problemática. Assim, entende-se que foi desconsiderado o papel da escola de informar cientificamente o estudante e de apresentar situações para se colocarem críticos da realidade e participar da busca de possíveis transformações para a melhoria da sociedade.

Considerando-se o dispositivo de aprendizagem implementado pela a Secretaria de Educação de Minas Gerais, entende-se que tem relevância trazer a questão da aprendizagem. Acredita-se que o estudante constrói o seu aprendizado a partir de uma interpretação inteligente e sistemática daquilo que vê, ouve e experimenta. Assim, pensa-se que apenas assistir a vídeos e fazer exercícios escritos, talvez não sejam suficientes para a promoção de um aprendizado eficiente, pois compreende-se que faltam os processos interacionais sociais que também são necessários para assimilação e aprendizagem escolar. De acordo com Machado (2001, p. 60), "o conhecimento é fruto de uma progressão sucessiva de etapas que caminham para a objetivação dos conceitos". Nessa perspectiva, os estudantes precisam usar o potencial das ferramentas que estão sendo disponibilizadas a eles, tanto aquelas online quanto offline, para inventarem e até construírem as suas teorias e explicações.

Cabe destacar que não basta o aluno apresentar respostas certas, é importante saber como se chega à resposta. Nesse ponto é que entra o papel mediador do professor, que em um atendimento distante do estudante pode não ser eficaz. Para Machado (2001), a aprendizagem é uma atividade psicológica que revela as peculiaridades de cada aprendiz ao se adaptar à diversidade dos objetos de conhecimento. Nesse viés, é necessário respeitar as limitações de cada um, suas aptidões pessoais, necessidades e interesses (MACHADO, 2001).

\section{CONSIDERAÇÕES FinAIS}

A análise realizada possibilitou relatar o modo como o tema Coronavírus foi abordado nas atividades do Planos de Estudos Tutorados-Caderno nº1, do Ensino Fundamental Regular Anos Finais do Estado de Minas Gerais. Observou-se que, nas atividades que fazem referência ao tema, não houve um aprofundamento do assunto, de modo a favorecer o conhecimento acerca do comportamento do vírus e da pandemia da COVID-19. O tema foi utilizado na maioria das questões como suporte textual.

Notou-se que o assunto apareceu em diversas disciplinas, o que se compreendeu ser um ponto relevante. Contudo não foi apresentado na disciplina História e apareceu pouco na disciplina Ciências. Tomando-se por base a observação que se realizou, compreendeu-se que poderia ter havido um enfoque histórico, considerando a ocorrência de pandemias no passado, 
por meio do qual o estudante pudesse estabelecer analogias e compreensões relativas ao papel da ciência para a solução de problemas da humanidade. As informações poderiam ter ocorrido de modo mais detalhado, considerando a ciência não como ponto final, com respostas acabadas, mas como ponto de novos questionamentos e de busca de novas respostas.

A partir da análise, entendeu-se que o tema foi abordado nos cadernos dos planos tutorados de forma superficial e não colocou o estudante numa postura criticidade indagativa. O saber científico foi apresentado para os estudantes sem levar em consideração os seus fundamentos lógicos, seu valor e sua importância e, portanto, pode não favorecer a construção, por parte do estudante, do conhecimento acerca do vírus em questão e da relevância do problema para a sociedade e para o mundo. Desse modo, refletindo-se sobre os resultados que foram descritos, entendeu-se que outros estudos acerca dos cadernos dos PTEs do Estado de Minas Gerais e, talvez, de outros Estados brasileiros possam ser realizados e levados à discussão, visando melhoria na qualidade do ensino e da aprendizagem em tempo de pandemia e, principalmente, em tempos ditos "normais".

\section{REFERÊNCIAS}

AUSUBEL, David Paul. A Aquisição e Retenção do Conhecimento: Uma perspectiva cognitiva. $1^{\mathrm{a}}$ ed. Lisboa-PT. Plátano Edições Técnicas, 2003.

BADIN, Ana Maria Andreola; PEDERSETTI, Simone; SILVA, Melissa Borges da. Educação Básica em Tempos de Pandemia: Tentativas para Minimizar o Impacto do Distanciamento e Manter o Vínculo entre os Alunos, as Famílias e a Escola. In: PALÚ, Janete; SCHÜTZ, Jenerton Arlan; MAYER, Leandro (organizadores). Desafios da educação em tempos de pandemia. Cruz Alta: Ilustração, 2020.

BHABHA, Homi K. O Local da Cultura. $5^{\text {a }}$ reimpressão. Belo Horizonte: Editora da UFMG, 2010.

COUTO, Edvaldo Souza; COUTO, Edilece Souza; CRUZ, Ingrid de Magalhães Porto. \#Fiqueemcasa: educação na pandemia da Covid-19. Interfaces Científicas, V.8, N.3, Fluxo Contínuo, p. 200 - 217, Aracaju, 2020. Disponível em:

https://periodicos.set.edu.br/index.php/educacao/article/view/8777/3998. Acesso em 24 jun. 2020.

KIRCHNER, Elenice Ana. Vivenciando os Desafios da Educação em Tempos de Pandemia. In: PALÚ, Janete; SCHÜTZ, Jenerton Arlan; MAYER, Leandro (organizadores). Desafios da educação em tempos de pandemia. Cruz Alta: Ilustração, 2020.

MACHADO, Nilson José [et al.]. Pensando e Fazendo Educação de Qualidade. São Paulo: Moderna, 2001. 
MINAS GERAIS. Resolução SEE $\mathbf{n}^{\mathbf{0}}$ 4.310/2020. Secretaria de estado de Educação de Minas Gerais. Belo Horizonte: SEE-MG, 2020.

MINAS GERAIS. Secretaria de Educação do Estado de Minas gerais. SRE Diamantina - MG. Regime Especial de Atividades não Presenciais. Disponível em:

https://srediamantina.educacao.mg.gov.br/index.php/2-dire/uncategorised/144-regimeespecial-de-atividades-nao-presenciais-reanp-e-divulgado-oficialmente-para-toda-acomunidade-escolar. Acesso em:20 jun. 2020.

SILVA, Francisco Thiago. Currículo de transição: uma saída para a educação pós-pandemia. Revista EDUCAmazônia - Educação Sociedade e Meio Ambiente, Ano 13, V. 25, N. 1, Jan-Jun, pág. 70-77, 2020. Disponível em: https://periodicos.ufam.edu.br/index.php/ educamazonia/article/view/7666/5363. Acesso em 24 jun. 2020.

VIEIRA, Letícia; RICCI, Maike C. C. A Educação em Tempos de Pandemia: Soluções Emergenciais pelo Mundo. Editorial, abr. 2020. OEMESC- Observatório do Ensino Médio em Santa Catarina, 2020. Disponível em:

https://www.udesc.br/arquivos/udesc/id_cpmenu/7432/EDITORIAL_DE_ABRIL_Let_cia Vieira_e_Maike_Ricci_final_15882101662453_7432.pdf. Acesso em: 19 out. 2020.

Recebido em: 7 de julho de 2020. Aprovado em: 7 de dezembro de 2020. 